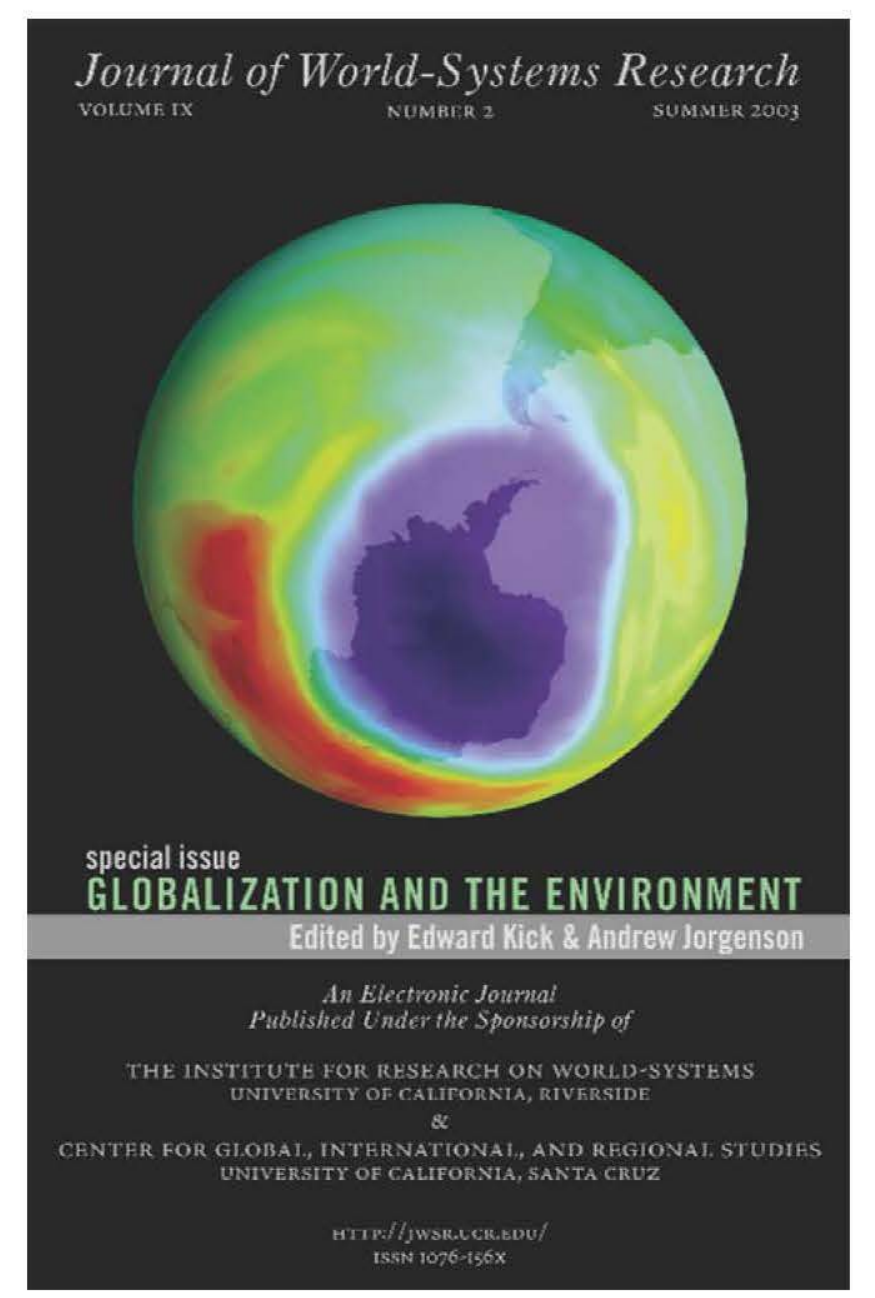

ABSTRACT

This article contrasts two fundamentally different understandings of economic growth and "development" that lead to diametrically opposed approaches to how to deal with global ecological deterioration. One is the currently hegemonic perspective of neoclassical economic theory, which has been used to advocate growth as a remedy for environmental problems. The other is the zero-sum perspec tive of world-system theory, which instead suggests that growth involves a displacement of ecological problems to peripheral sectors of the world-economy. The article begins by sketching the history of these two perspectives in recent decades and reflecting on the ideological and epistemological contexts of their appearance and different degrees of success. It then turns to the main task of critically scrutinizing some of the foundations of the neoclassical approach to environmental issues, arguing that its optimistic view of growth is based on faulty logic and a poor understanding of the global, physical realities within which money and the capitalist world-system operate.

\section{Cornucopia or Zero-Sum Game? The Epistemology of Sustainability*}

Alf Hornborg

\section{INTRODUCTION}

$\mathrm{n}$ the very first days of the new millennium, newspapers in Sweden-as elsewhere-devoted some editorial space to assessing the state of the world. The leading daily Dagens Nybeter expressed puzzlement over a survey showing that a large percentage of Swedish youth were not particularly optimistic about the future. Why this worry about global ecology, the editor asked, now that the pessimistic prophecies of the Club of Rome could be dismissed once and for all? Yet, the previous day, in the same newspaper, an environmental journalist had observed that the state of the world environment is considerably worse than most people in the richer countries realize. The problem, he said, is that these people can choose to stay ignorant about the South's environment simply by switching television channels. Here were thus two very different messages on global ecology offered in the same newspaper.

Similarly contradictory were its assessments of global inequality. On New Year's Eve, an editorial proclaimed that the Marxist notion that the affluence of the rich is based on other people's impoverishment could be decisively dismissed. In the very same issue of Dagens Nybeter, however, an entry with the heading

Alf Hornborg
Human Ecology Division
Lund University
Finngatan 16
22362 Lund, Sweden
Alf.Hornborg@humecol.lu.se
http://www.humecol.lu.se/

* I would like to thank Rowman \& Littlefield Publishers for permission to reprint this text, originally published as chapter 2 in my book The Power of the Machine: Global Inequalities of Economy, Tecbnology, and Environment, AltaMira Press, 2001 (see http://www.altamirapress.com/).

JOURNAL OF WORLD-SYSTEMS RESEARCH, IX, 2, SUMMER 2003, 205-2I6 Special Issue: Globalization and the Environment

bttp://jwsr.tucr.edu/

ISSN I076-I56X

(C) 2003 Alf Hornbor 
"Renaissance for Marx" reports that a new biography of Karl Marx is the season's bestseller in Britain. The next day, there is a two-page interview with the Marxist sociologist Manuel Castells, introduced as "the hottest intellectual in the world," who perceives the present as characterized by a process of unprecedented social polarization and warns that the conflict may soon become critical. How are we to understand these schizophrenic messages on global environment and development that surround us as we enter the third millennium?

Judging from mainstream public discourse, faith in technology and economic growth seems stronger than ever. The WCED conference in Rio de Janeiro in I992 - the climax of three decades of negotiations on global issues-solidified an official creed suggesting that growth is the general solution to environmental problems (World Commission on Environment and Development 1987). The key concept, of course, became "sustainable development." This creed is now often referred to as "ecological modernization" (Hajer 1995). Meanwhile, however, there remains a widespread countercurrent of skepticism, passive and invisible for the most part, but remarkably powerful when demonstrating strength enough to overturn the important World Trade Organization (WTO) meeting in Seattle on the eve of the old millennium. Many people must be asking themselves today if the critics in the I97os were really so completely wrong about the conflict between growth and environment, and if WCED's interpretation of global issues is really the only one possible. The I970s saw a widespread concern that the economic growth of industrial sectors occurred at the expense of the Third World and the global environment. According to the WCED paradigm, however, growth is of benefit for both the global economy and global ecology. We may refer to the two paradigms as "zero-sum game" versus "cornucopia" theories of growth.

It might seem as if the choice between zero-sum game and cornucopia models should be a simple empirical question. What do the data say? It no longer seems feasible, however, to identify "simple empirical" questions in the social sciences. The global interconnections are too complex. The opposite camp generally seems to be able to turn each specific piece of information inside out by putting it in a different context and approaching it from a different perspective.

In a book the subtitle of which is Measuring the Real State of the World, Danish statistician Björn Lomborg (200I) contradicts Worldwatch Institute, Greenpeace, and the World Wide Fund for Nature by suggesting that what have been perceived as global problems of inequality and environmental deterioration are mostly illusions. One by one, he dismisses all our worries about resource depletion, per capita food production, increasing gaps between rich and poor, deforestation, acidification, species extinction, chemical pollution, and global warming. The conclusion that not just some of but all these worries are illusory is
Cornucopia or Zero-Sum Game?

indeed remarkable. It is obvious that both the compilation and the interpretation of statistics to a large extent boil down to whether we wish to see this or that pattern. This is not a simple question of manipulation, but of a fundamental human desire to see verified by data the patterns we imagine to exist in the world. But how do we choose these patterns or interpretations to begin with?

To the extent that we do choose our models, it is evident that our considerations are not concerned solely with the criterion of credibility. We like to think that our most fundamental criterion for "truth" is whether a specific interpretation of causal connections can explain the most aspects of our global predicament, but the widespread paradigm shift that has occurred since the I970s instead suggests that a more crucial consideration is which interpretation we can live with. In the industrialized nations in the I960s and early I970s, there was an existential space, so to speak, for radical criticism. Especially among younger people, there was a widespread faith in the capacity of collective, social movements to transform fundamental structures in society. When faith in the future and collective change withered in the mid-I970s, a great many people in the North probably found the idea that their affluence was based on the impoverishment of the South and the global environment unbearable and thus impossible to accept. An important factor underlying this shift was the increasing mobility of globalized capital. Faced with the threat of unemployment, local populations everywhere grew more careful in their criticism of power (cf. Bauman 1998). To the extent that some of the indignation over environmental problems and global inequality persisted, it was generally transformed from revolutionary fervor to resignation. Globalization thus implied contradictory impulses that condemned both the embittered in the South and the conscience-stricken in the North to a predicament of perpetual, cognitive dissonance. Through media they came into ever-closer contact with global inequalities, while at the same time it seemed increasingly evident to them that there was virtually nothing they could do about them.

This may explain some of the market for the new genre of "green-bashing," counter-environmentalist books like Lomborg's. Many readers probably felt comfortable with Lomborg's wholesale denial of environmental concern. But there are more subtle ways of disarming indignation than simple denial, What ecological modernization has achieved is a neutralization of the formerly widespread intuition that industrial growth is at odds with global ecology. The environmental concern of young people is now being redirected into special educational establishments designed to promote the message that the adverse effects of economic growth can best be amended with more growth. The discursive shift since the 1970s has been geared to disengaging concerns about environment and development from the criticism of industrial capitalism as such. But the central 
question about capitalism should be the same now as it was in the days of Marx: Is the growth of capital of benefit to everybody, or only to a few at the expense of others? However much contemporary debate tries to sweep this question under the carpet, it will continue to reappear, albeit in new forms. Since Marx's time, it has been extended primarily in two directions. On one hand, questions of injustice and unequal exchange have transcended the local relation between worker and capitalist and been applied to the global exchange between industrial centers and their peripheries; on the other hand, there have been attempts to include global ecology in the same analysis.

Judging from much contemporary public discourse, asking questions about unequal exchange would seem obsolete or irrelevant for today's world. Concepts like "imperialism" and "exploitation" have well-nigh vanished in the sustainababble following the Rio conference. Yet, Marx's basic intuitions seem impossible to eradicate, however hard the neo-liberal discourse of the I980s and I990s has tried. Björn Hettne (1990) shows how thinking about global development has oscillated through the past century. In the mid-twentieth century, the dominant paradigm was based on a Eurocentric concept of modernization that, through the work of Walt Rostow and others, translated global inequality into a temporal axis that defined the future for the "underdeveloped" countries. "Development aid" was viewed as a global, Keynesian welfare policy that in the end would be of benefit both to the poor and to the rich. In the I970s, the dependency theory of Gunder Frank, Samir Amin, and others gained prominence in connection with demands for a "New Economic World Order" and the success of the Organization of Petroleum Exporting Countries (OPEC) in bargaining oil prices. It argued for a kind of zero-sum perspective, in which the affluence of the "metropolis" or "core" was to be understood as based on the impoverishment of the "satellite" or "periphery" In the I980s, however, a neo-liberal "counterrevolution" swept away both Keynesianism and dreams of a new world order. Milton Friedman, the World Bank, and the International Monetary Fund (IMF) redefined poverty as mismanagement and opened the world to an even tougher brand of capitalism. In I99o, Hettne believed that a new counterpoint may have been emerging in the form of "anti-modern" and marginalized groups such as environmental movements, feminists, peasants, indigenous peoples, and the unemployed. In the decade that followed, however, the most publicized criticism of unfettered capitalism came from multimillionaire George Soros, who expressed deep worries about the omnipotence of money and the growing vulnerability of globalized capitalism. Nevertheless, by the end of the decade, it seemed that Hettne's prediction was perhaps being substantiated by the globalized, motley alliance of anticapitalist demonstrators who captured the headlines in Seattle.

\section{THE ZERO-SUM PERSPECTIVE: FAILURES AND PROSPECTS}

It is valid to ask why dependency theory has lost so much of its former influence in development studies. Was it because the development strategy it inspired - isolationism - proved such a failure? Hettne (1990) reminds us that the attempts of Chile and Nicaragua at "de-linking" were soon countered by measures from more powerful nations aiming at "destabilization" of these deviants. Meanwhile, the Newly Industrialized Countries of southern Asia were rewarded for their opportunism and willingness to submit to the conditions of global capital. Instead of dismissing dependency theory, we might refer to Wallerstein's (1974) observation that "development" is to advance from periphery to semiperiphery, Conversely, we can understand the current "underdevelopment" of major parts of the former Soviet Union as a process of peripheralization. Seen in this perspective, development and underdevelopment are the results of movements of capital in the world system, and the shifts of affluence in the 1980s and I99os can be seen as a confirmation not of the recommendations of dependency theory but of its fundamental, zero-sum model. There is evidently an inclination to dismiss the theoretical understanding of the dynamics of the world system - like the Marxist perspective as such —as soon as the practical implications someone has derived from it prove a failure. This is tragic, because it should be quite feasible to arrive at a correct analysis of a problem without (yet) having developed a good solution.

Brewer (1990) lists several major types of criticism that have been directed at dependency theory. According to Brewer, the argument that core areas have a "monopoly" and that they "exploit" their peripheries does not include explicit, theoretical definitions of these concepts, but rather amounts to tautology. It is particularly problematic that the theory does not define a central concept like "surplus" or explain in which ways metropolis-satellite relations are to be seen as projected in geographical space. Brewer argues that nations are not really relevant entities in this context. He also criticizes dependency theory for not being able to explain why certain countries seem to be able to break free from their dependency.

The critics are right in that there is an element of tautology in dependency theory as long as the "core" or "metropolis" is defined as the place where accumulation occurs, while "accumulation" is defined as what occurs in the core. There are, however, more substantial specifications, such as the focus of the PrebischSinger theorem on the structural logic of exchange relations between industrial sectors and those sectors that deliver their raw materials. It is nevertheless true that the concept of "surplus" - that which is transferred from periphery to core-is not defined in a clear manner. For more or less self-sufficient subsis- 
tence economies, Paul Baran (1957) offered a simple definition of "surplus" as the difference between what is produced and what is consumed, but for societies engaged in production for the market, it is necessary to refer to some measure other than money (market prices) to be able to argue that a particular exchange is exploitative. To solve this problem and produce a more rigorous argument, dependency theory could build on concepts from the natural sciences such as energy (see below).

Brewer is also right in that nations are not relevant units, simply because core-periphery relations cannot in any but the crudest manner be represented in terms of spatially demarcated areas. Gunder Frank (Frank I966) instead argued that they were to be conceptualized as polarizing exchange relations at different levels of scale both within and between countries. These polarized flows can be traced even in local contexts such as the exchange between a hacienda owner and his workers. This geographical indeterminacy has been accentuated by the increasing globalization of capital flows, which make it all the more difficult to identify the "core" as a spatially distinct social unit or actor. There is no necessary congruity between the spaces where the appropriated resources are accumulated, where the capitalists live, and where they have their bank accounts.

Yet capital continues to generate obvious spatial patterns, as anyone can see on nightly satellite photos. Such images lend concrete, visual support, for instance, to statistics which say that the average American consumes 330 times more energy than the average Ethiopian. When new parts of the world system succeed in attracting capital - that is, when they "develop"-it shows clearly in the satellite images, as in the strong contrast between the dark northern and luminous southern half of the Korean peninsula. It must be of relevance to world system theory that the United States' share of world energy consumption is $25 \%$, while $20 \%$ of the world's people do not have access to enough energy to successfully maintain their own body metabolism. This obviously also has an environmental dimension. The richest $20 \%$ of the world's population consume $86 \%$ of the aluminium, $8 \mathrm{I} \%$ of the paper, $80 \%$ of the iron, and $76 \%$ of the lumber (Brown 1995). Per capita carbon dioxide emissions in 1990 were around five tons in the United States but only O.I tons in India. (Remarkably, however, many people in the industrialized North continue to believe that it is their mission to educate people in the South on how to live and produce sustainably, as if the North was setting a good example, and as if environmental problems in the South were the result of ignorance rather than impoverishment.)

If rates of energy dissipation are an essential component in the inequitable dynamics of the world system, it must be a central theoretical challenge to integrate perspectives from the social and natural sciences to achieve a more complete understanding of capital accumulation. An explicit attempt to connect dependency theory and energy flows is Stephen Bunker's (1985) study of underdevelopment in the Amazon. He shows how the "extractive" economies of peripheral Amazonia are at a systematic disadvantage in their exchange with the "productive" economies of industrialized sectors. The flows of energy and materials from the former to the latter tend to reduce complexity and power in the hinterland while augmenting complexity and power in the core. Extractive economies generally cannot count on a cumulative development of infrastructure as can the productive economies in the core, because economic activities in the former are dispersed and shifting according to the location of the extracted materials. As the stocks of natural resources become increasingly difficult to extract as they are depleted, an intensification of extraction will tend also to increase costs per unit of extracted resources, instead of yielding the economies of scale associated with intensification in the industrial core. Bunker's analysis suffers from his inclination to view energy as a measure of economic value (cf. Hornborg 200I), but in other respects his underlying intuition is valid. The luminous agglomerations of industrial infrastructure in the satellite photos are the result of uneven flows of energy and matter, and these processes of concentration are self-reinforcing, because the increasingly advantageous economies of scale in the center progressively improve its terms of trade and thus its capacity to appropriate the resources of the hinterland. Extractive economies are thus pressed to overexploit nature, while those parts of the landscape in industrial nations that have not been urbanized can instead be liberated from the imperative to yield a profit and rather become the object of conservation programs. Environmental quality is thus also an issue of inequitable global distribution. "Environmental justice" is merely an aspect of the more general problem of justice within the framework of world system theory.

\section{THE CORNUCOPIA MODEL: IS GROW'TH REALLY GOOD FOR THE ENVIRONMENT?}

The preceding arguments to me seem logically coherent, credible, and persuasive. I am thus all the more curious about the alternative interpretation-what I refer to as the "cornucopia" model, that is, the currently hegemonic worldview that declares capital accumulation in the core completely innocent with regard to poverty and environmental problems in the South. An unusually accessible and instructive example of this worldview comes from Swedish economist Marian Radetzki (1990, 1992), whose essays address the overarching question of whether there is a positive or negative correlation between economic growth and environmental quality. He observes that the worst environmental destruc- 
tion occurs in the poor rather than the richer countries and concludes from this that environmental quality improves as the economy grows and becomes "denser." The explanation, says Radetzki, is that the intensity of environmental damage decreases as per capita GNP increases. This intensity is defined as the quantity of "environmental resources" that are expended to generate one unit of GNP. Intensity of environmental wear is reduced because with growth there is a tendency for "material intensive" production to be replaced by the production of services. Meanwhile, there is an increase in the willingness of consumers to pay for a clean environment the more affluent they become, and environmental policies in wealthier nations encourage the development of new environmental technologies. Instead of intensifying the consumption of "environmental utilities," these nations can substitute services from "human and physical capital" for those of natural resources. For this reason, forests and other natural resources are not diminishing in the industrialized countries. Instead, much of the landscape is reverting to something approaching a "natural state" Growth and technological development make it possible to invest, for example, in aquaculture instead of depleting wild fish stocks, plantations instead of cutting down rain forests, and swimming pools instead of exploiting natural beaches. Radetzki concludes that it is thus possible to maintain continued economic growth, and that there is in fact an unlimited potential for "sustainable growth"

Radetzki's texts are useful reading because they summarize, in a nutshell, the logic of an economist's approach to the relation between growth and environment in a way that makes it very clear how the basic assumptions of the cornucopia model differ from those of the zero-sum game model. An essential difference is evidently Radetzki's assumption that an economic activity and its environmental consequences coincide geographically. If environmental quality is relatively high where growth is high (and vice versa), he concludes that growth reduces environmental damage, instead of (or perhaps without hesitating at?) the equally feasible interpretation that the environmental consequences of growth have been shifted to other parts of the world system. It is in fact unclear if Radetzki discusses the "environment" as a local or a global phenomenon. It seems unlikely that he would consider it a solution to environmental problems to have them shifted to someone else's backyard, but some of his arguments leave it an open matter. He writes, for instance, that growth makes it feasible to legislate so as to increase production costs for polluting industries, which has led to "a considerable shift of environmentally damaging activities from richer countries to poorer, where costly environmental policies are absent" (Radetzki 1990: 8-39; my translation). "The environment," he continues, "is to a very large extent a concern of the wealthy." It is to be noted that this reasoning is offered in a context where he argues for growth as a solution to environmental problems. If we assume that Radetzki is
Cornucopia or Zero-Sum Game?

not advocating a continued shifting of pollution to poorer countries, as at least one prominent World Bank economist ${ }^{1}$ actually has done, we must draw the conclusion that his vision of the future is that all people in the world shall be "wealthy." This strikes me as impossibly naive, considering that the gap between rich and poor continues to widen. Between 1947 and 1987 , the ratio of per capita income between the richest and the poorest countries increased from 50:I to I30: I (Adams I993).

Not only is the growth recipe in a global perspective politically naive, but it also disregards the fundamental objection that processes of resource depletion and environmental destruction will increase with wealth, after all, even if they are shifted to other locations and thus vanish from sight. We have already mentioned emissions of carbon dioxide, which are 50 times higher for the average American than for the average citizen of India. Mathis Wackernagel and his colleagues have estimated that if all the people in the world were to reach the same standard of living as that in the richest countries, they would require three additional Earths (Wackernagel and Rees 1996; Wackernagel et al. 1997). Although the global access to "ecoproductive" land decreased from 5 to $I_{*} 7$ hectares per capita between I900 and I990, the per capita "footprints" of the richer countries increased from I to between 4 and 6 hectares (Wackernagel et al. 1997). To accumulate money is ultimately to be able to increase one's claims on other people's resources. It is evident that these claims cannot increase indefinitely, because the resources are not unlimited.

When Radetzki argues that there is a positive connection between economic growth and environmental quality, we must ask what this connection looks like. Does growth simply dissolve environmental problems as such (and not just locally), or does it shift them to poorer areas? Again and again we are inclined to interpose the crucial question: "Where?" Where is environmental quality improved? Where is it realistic to build artificial micro-environments (such as swimming pools) that reduce wear on the local environment, and where are the natural resources procured with which to build them? Where can the landscape revert to a "natural state," and from where are the resources appropriated that substitute for its former yields?

Two fundamental objections can be directed at Radetzki's argument, both of which concern the capacity of the market and monetary measures to con-

1. On December I2, I99I, World bank chief economist Lawrence Summers, using inpeccable economic arguments, suggested that the World Bank should be encouraging a migration of "dirty" industries to less developed countries. 
ceal other dimensions of economic processes. When he claims that intensity of resource use decreases as per capita GNP increases, we may forget that whereas resource use is a physical reality, GNP is "only" a symbolic reality. GNP is ultimately a measure of the terms of trade (world market prices) that a country has been able to secure for its products and services in exchange for those of other countries. GNP is thus a measure that reflects a country's position in socially negotiated, global exchange relations. Rather than say that intensity of resource use decreases per unit of GNP per capita, we can just as well say that the prices of a nation's products increase faster than its resource use. This could be understood as an expression of increasing margins of profit in industrial sectors as a consequence of increasingly advantageous terms of trade vis-à-vis the raw materials sectors. To conclude, from what Radetzki says about the relation between resource consumption and GNP, that growth is good for the environment would be tantamount to saying that it does not matter if environmental damage increases, as long as GNP increases faster. But the crucial question, of course, should be whether environmental damage increases in absolute terms.

The second objection can be directed at the claim that growth and technological development make it possible to substitute the services of "human and physical capital" for those of nature. The issue boils down to what we mean by "substitute." From a local perspective it might appear possible to "substitute" labor and capital for land; this approach became fundamental to industrial society from the very start. But to the (large) extent that these extra inputs of labor and technology are made possible by utilizing natural resources from another part of the world system (e.g,, by importing food for the labor force or fossil fuels for the machines), it is questionable if it is valid to claim that labor and capital really can "substitute" for land. From a global and physical perspective it is to a very large extent an illusion that the stocks of natural resources can be increased with the help of more labor and capital. The faith in "substitution" shows the extent to which economic science has emerged as a local (originally British) perspective that really does not ask questions about the global management of resources beyond the territory of the individual nation.

As long as the primary knowledge interest of a science is to generate growth strategies for individual companies or nations, it is only natural that its fundamental assumptions should differ from those required of a science of global resource management. Only when the world is viewed as a finite and in certain respects closed system are we able to discover that what is locally perceived as a cornucopia may in fact be a component in a global zero-sum game. This discovery must be allowed to shake the very foundations of the two centuries-old assumptions of economics. We must finally ask ourselves whose knowledge interests our research is to serve: the individual corporation, the individual nation, or all of humanity?
To build an understanding of global interconnections between ecology and economy that serves the knowledge interests of global resource management and environmental justice, rather than national or corporate growth, we need to reconceptualize several aspects of development theory. Instead of visualizing nations as autonomous territories the environmental condition of which reflects, in a simple and immediate way, their own economic activities, we must learn to think of the world as a system, in which one country's environmental problems may be the flip side of another country's growth. Those of us who live in the privileged, affluent core would be amiss to use our green forests and fertile fields as evidence that worries about global ecology are unfounded, because the liberation and recovery of previously impoverished landscapes to a large extent has been made feasible by the import of resources from peripheral areas both within and between nations. The most difficult but perhaps also most important point is to learn to view technological development as an expression of capital accumulation, and thus ultimately of unequal relations of exchange with less "developed" sectors of world society. Growth and technological development in some parts of the world system are thus organically linked to underdevelopment and environmental deterioration in others. If we want to work for global, environmental justice, we first need to develop a new theoretical understanding of technology as a redistribution of resources made invisible by the vocabulary and ideology of the market. This unequal exchange of resources can be made visible only by identifying, beneath the flows of monetary exchange value, measures of real resources such as energy, labor time, and hectares of productive land.

I am inclined to think that our preparedness to abandon the "cornucopia" model of growth and technology for a "zero-sum game" perspective will be connected to wider, existential concerns. It would probably be naive to think that a majority of people in the wealthier nations, out of a pure quest for truth and solidarity with the distant and anonymous masses of the South, would choose an interpretation of reality that could be expected to subject them to deep and continuous, ethical conflict. Perhaps their affluence would first have to be seriously jeopardized in order for such a paradigm shift to occur at any substantial scale. Above all, we may assume that the zero-sum game perspective will be acceptable only if accompanied by a concrete and attractive vision of how the fundamental logic of capital accumulation can be transformed or domesticated in the name of global solidarity, For a large part of the twentieth century, the Marxist worldview offered one such vision that attracted a substantial part of humanity. Very few would today deny that that vision was incomplete and misguided in several respects. If we were to endeavor a new vision, it would probably have to proceed further in its questioning not only of the market, but of even more fundamental, modern institutions such as money and technology. To domesticate the market, 
a long-term aim might be to split it horizontally so as to render local subsistence and global communication two parallel but distinct and incommensurable domains. Changes in that direction could amount to an immunization of local ecosystems and human life-worlds vis-à-vis the ravages of global capital flows. This would also serve to restrain the unevenly distributed growth of technological infrastructure, so that the machinery of the wealthier nations does not continue to expand at the expense of the very life-space of the global poor.

\section{REFERENCES}

Adams, N. A. (1993). Worlds Apart: The North-South Divide and the International System. Zed Books.

Baran, P. (1957). The Political Economy of Growth. Penguin.

Bauman, Z. (1998). Globalization: The Human Consequences. Polity Press.

Brewer, A. (1990). Marxist Theories of Imperialism: A Critical Survey. $2 \mathrm{~d}$ ed. Routledge.

Brown, L. B. (1995). State of the World ' 95 . Worldwatch Institute.

Bunker, S. G. (1985). Underdeveloping the Amazon: Extraction, Unequal Exchange and the Failure of the Modern State. University of Chicago Press.

Frank, A.G. (I966). "The Development of Underdevelopment”, Monthly Review 18:I7-3I.

Hajer, M. A. (1995). The Politics of Environmental Discourse: Ecological Modernisation and the Policy Process. Clarendon Press.

Hettne, B. (1990). Development Theory and the Three Worlds. Longman.

Hornborg, A. (200I). The Power of the Machine: Global Inequalities of Economy, Technology, and Environment. AltaMira/Rowman \& Littlefield.

Lomborg, B. (200I). The Skeptical Environmentalist: Measuring the Real State of the World. Cambridge University Press.

Radetzki, M. (1990). Tillväxt och miljö. SNS Förlag.

Radetzki, M. 1992. "Economic growth and environment." In International Trade and the Environment, edited by P. Low. The World Bank.

Wackernagel, M., \& W. E. Rees (1996). Our Ecological Footprint: Reducing Human Impact on the Earth. New Society Publishers.

Wackernagel, M., L. Onisto, A. Callejas Linares, I. S. López Falfán, J. Méndez García, A. I. Suárez Guerrero, \& M. G. Suárez Guerrero (1997). Ecological Footprints of Nations. Centre for Sustainability Studies, Universidad Anáhuac de Xalapa, Mexico.

Wallerstein, I. M. (1974)."The Rise and Future Demise of the World Capitalist System: Concepts for Comparative Analysis", Comparative Studies in Society and History 16; $387-415$.

World Commission on Environment and Development (WCED) (1987). Our Common Future. Oxford University Press. 